УДК $630 * 524$

ОЦЕНКА РАНГОВОГО ПОЛОЖЕНИЯ ДЕРЕВЬЕВ В ДРЕВОСТОЕ ПРИ ИССЛЕДОВАНИИ ИХ ФИТОМАССЫ

Нагимов 3.Я., Артемьева И.Н., Шевелина И.В., Нагимов В.3.

ФГБОУ ВО «Уральский государственный лесотехнический университет», Екатеринбург, e-mail:nagimovzy@m.usfeu.ru

\begin{abstract}
При построении нормативов надземной фитомассы деревьев применение традиционных методов лесотаксационной науки, разработанных для определения объёмов древесных стволов, в которых в качестве основных объёмообразующих показателей используются только их линейные размеры (диаметр и высота), не совсем корректно. В частности, фитомасса крон зависит не только от размеров деревьев, но и от их развития и рангового положения в древостое. В результате проведённых исследований установлено, что ранг деревьев одинаковой толщины и их положение в пологе изменяются в зависимости от условий местопроизрастания (типов леса), возраста и густоты древостоев. В онтогенезе древостоев наблюдаются экологический, возрастной, густотный сдвиги рангов деревьев одинакового диаметра. Изменчивость массы крон, а следовательно, их структурных частей (ветвей, хвои и генеративных органов) корректно связывать с высотой и диаметром деревьев, только в древостоях одного типа леса при незначительной возрастной гетерогенности деревьев. Оценка изменчивости и особенностей накопления фитомассы крон в рамках естественных возрастных рядов роста и развития древостоев (в древостоях разного возраста, произрастающих в однородных лесорастительных условиях), корректно проводить с учетом возраста, диаметра и высоты деревьев. В подобных исследованиях, охватывающих множество естественных рядов развития, возникает необходимость в использовании дополнительного показателя, характеризующего качество условий местопроизрастания класса бонитета насаждений. Ранговое положение, размеры и фитомасса кроны, а также соотношение ветвей и хвои в кроне у деревьев одинаковой толщины изменяются в зависимости от густоты, возраста и условий местопроизрастания древостоев.
\end{abstract}

Ключевые слова: древостой, диаметр, высота, фитомасса деревьев, лесотаксационные нормативы, ранг деревьев

\title{
ESTIMATION OF RANK POSITION OF TREES IN STAND PHYTOMASS RESEARCH
}

\author{
Nagimov Z.I., Artemyeva I.N., Shevelina I.V., Nagimov V.Z. \\ Ural State Forest Engineering University, Yekaterinburg, e-mail: nagimovzy@m.usfeu.ru
}

\begin{abstract}
When constructing standards for aboveground phytomass of trees, the use of traditional methods of forest taxation science, developed to determine the volume of tree trunks and in which only their linear dimensions (diameter and height) are used as the main volume-forming indicators, is not entirely correct. In particular, the phytomass of the crowns depends not only on the size of the trees, but also on their development and rank position in the tree stand. As a result of the conducted studies, it was found that the rank of trees of the same thickness and their position in the canopy vary depending on the conditions of the growing area (forest types), age and density of stands. In the ontogenesis of stands, there are ecological, age, and density shifts in the ranks of trees of the same diameter. The variability of the mass of crowns, and, consequently, their structural parts (branches, needles and generative organs) is correctly associated with the height and diameter of trees, only in stands of the same type of forest with insignificant age heterogeneity of trees. The assessment of the variability and features of the accumulation of crown phytomass within the natural age series of growth and development of stands (in stands of different ages growing in homogeneous forest growing conditions) is correctly carried out taking into account the age, diameter and height of trees. In such studies, covering a variety of natural development series, there is a need to use an additional indicator that characterizes the quality of the growing conditions - the class bonitet. The rank position, size and phytomass of the crown, as well as the ratio of branches and needles in the crown of trees of the same thickness vary depending on the density, age and conditions of the growing area of the stands.
\end{abstract}

Keywords: tree stand, diameter, height, phytomass of trees, forest taxation standards, rank of trees

На современном этапе развития лесохозяйственного производства актуальной задачей становится составление многовариантных и многофункциональных лесоводственно-таксационных нормативов, которые отражают динамику таксационных показателей и различных фракций фитомассы деревьев [1, 2]. В конструкции большинства лесотаксационных нормативов заложен принцип определения трудно измеряемых или не поддающихся прямым измерениям таксационных показателей на основе технологичных показателей (наиболее доступных и точно оцениваемых). При построении нормативов надземной фитомассы деревьев применение традиционных методов лесотаксационной науки, разработанных для определения объёмов древесных стволов, в которых в качестве основных объёмообразующих показателей используются только их линейные размеры (диаметр и высота), не совсем корректно. Это связано с тем, что диаметр и высота деревьев являются конечными результатами ростовых процессов в данном возрасте, а различные фракции фитомассы - это результаты роста 
за различные возрастные периоды. Возрастная гетерогенность фракций фитомассы наиболее выражена в кроне дерева. Поэтому оценка массы структурных частей кроны (ветвей, хвои, генеративных органов) на основе только морфометрических показателей может сопровождаться существенными ошибками. Фитомасса крон зависит не только от размеров деревьев, но и от их развития и положения в древостое.

Таким образом, при изучении фракционного состава надземной фитомассы деревьев наиболее перспективным является метод множественной регрессии, позволяющий оценивать влияние разных факторов на формирование тех или иных фракций фитомассы.

Цель исследования: обоснование показателей, являющихся наиболее информативными при оценке массы различных частей дерева, и которые могут быть включены в качестве определяющих факторов в математические модели при разработке лесотаксационных нормативно-справочных материалов.

\section{Материалы и методы исследования}

Исследования проводились в сосняках I-V классов бонитета на территории Среднего Урала и Западной Сибири. Таксационные показатели изучаемых насаждений изменялись в следующих диапазонах: средний возраст - от 14 до 140 лет; доля сосны в составе - от 53 до $100 \%$; полнота - от 0,55 до 1,00. Исследования проводились на пробных площадях (ПП). При их закладке ориентировались на требования ОСТ 56-69-83. На пробных площадях проводилась перечислительная таксация по элементам леса. У каждого дерева определялись диаметр и его положение в пологе по Крафту. Для выполнения задач исследования отбирались модельные деревья с учетом их распределения по ступеням толщины. У срубленных деревьев дополнительно к традиционным таксационным показателям определялся фракционный состав надземной фитомассы. Процедура обработки модельных деревьев для изучения их фитомассы представлена в наших работах [3, 4]. В работе использован массив данных по 1017 модельным деревьям. Математико-статистическая обработка проводилась в программах MO Excel и Statistica 10.0 [5].

\section{Результаты исследования и их обсуждение}

Фитомасса кроны и ее структурных частей (ветвей, хвои, генеративных органов) в значительной степени зависит от того, какое положение в пологе древостоя занимает дерево. Это положение в первую очередь связано с размерами ствола. Анализ экспериментальных материалов графо-аналитическим методом позволил установить некоторые закономерности в соотношениях диаметра и высоты деревьев, а также в динамике массы их структурных частей. В одновозрастных древостоях наблюдается устойчивое увеличение фитомассы стволов и крон деревьев с возрастанием их диаметра. Несмотря на значительную корреляцию фитомассы от диаметра, деревья одинаковой толщины могут существенно различаться как по массе стволов, так и по массе крон. Такое варьирование в одновозрастном древостое в значительной степени связано с колебаниями высоты деревьев. Общеизвестным фактом является, что в однородном по возрасту деревьев древостое высота стволов меняется не только с изменением величины ступеней толщины, но и в рамках отдельно взятой ступени. В специальной литературе это связывают как наследственными свойствами деревьев, так и их конкуренцией за свет, влагу и элементы питания.

В целом результаты проведенного анализа свидетельствуют, что при разработке многофакторных моделей для оценки надземной фитомассы деревьев по фракциям в качестве определяющих факторов (независимых переменных) могут быть использованы диаметр и высота стволов. В то же время общеизвестным фактом является наличие между диаметром и высотой деревьев корреляционной зависимости. Она может являться причиной отсутствия ортогональности между этими показателями. Из теории и практики множественного регрессионного анализа следует, что две переменные могут быть включены в регрессионное уравнение только при условии, когда коэффициент корреляции, характеризующий связь между ними, составляет не более 0,80 .

В этой связи для выяснения возможности использования высоты деревьев в качестве независимой переменной наряду с их диаметром, а также оценки ее действительной роли в уравнениях фитомассы нами были проведены специальные исследования. На первом этапе по материалам ПП с закартированными деревьями и общего массива данных модельных деревьев изучалась зависимость между диаметрами и высотами стволов. Установлено, что только 
на 4 ПП из 42 корреляционные отношения исследованных зависимостей оказались выше 0,80 (от 0,82 до 0,87). На всех остальных ПП они составили от 0,65 до 0,80 . По общему массиву 1017 модельных деревьев связь между диаметрами высотами стволов оценивается корреляционным отношением равным 0,67 \pm 0,047.

На втором этапе по материалам координатных ПП изучалась связь высоты древесных стволов (Н) с двумя таксационными показателями - диаметром (D) и площадью питания деревьев (Sp). Результаты графического анализа показали, что исследуемая зависимость логарифмированием эмпирических данных корректно приводится к линейному виду:

$$
\ln \mathrm{H}=\mathrm{a}+\ln \mathrm{D}+\operatorname{lnSp} .
$$

Анализ уравнений, полученных на всех ПП, показал, что коэффициент переменной $\mathrm{Sp}$ имеет отрицательный знак. Это свидетельствует о том, что при одинаковых значениях диаметра деревьев их высота закономерно уменьшается с увеличением площади питания (уменьшение густоты стояния окружающих деревьев).

На третьем этапе с использованием полного массива срубленных модельных деревьев оценивалась связь высоты стволов с тремя таксационными показателями - возрастом (A), диаметром и площадью питания. Оценка проводилась дифференцированно по классам бонитета с получением уравнений множественной регрессии. В качестве примера приведено трёхфакторное уравнение, полученное по показателям мо- дельных деревьев, взятых в древостоях третьего класса бонитета:

$$
\begin{aligned}
\ln \mathrm{H}= & -0,972+0,894 \ln \mathrm{D}+0,441 \ln \mathrm{A}- \\
& -0,297 \ln \mathrm{Sp}, \mathrm{R}^{2}=0,964 .
\end{aligned}
$$

Значения t-критерия Стьюдента при всех коэффициентах регрессии очень высокие: $\mathrm{t}_{0}=9,3, \mathrm{t}_{1}=23,7, \mathrm{t}_{2}=25,3, \mathrm{t}_{3}=12,9$. Bce включенные в уравнения факторы в высшей степени достоверны. По величине коэффициента детерминации $\left(\mathrm{R}^{2}\right)$ можно сделать заключение, что в однородных по условиям местопроизрастания древостоях изменчивость высот более чем на 96,5\% объясняется площадью питания, возрастом и диаметром деревьев. Отрицательный знак при коэффициенте Sp свидетельствует, что в однородных лесорастительных условиях при одинаковых значениях диаметра и возраста высота древесных стволов снижается с уменьшением густоты стояния деревьев (увеличением их площади питания).

Таким образом, в отдельно взятом древостое изменение высоты деревьев одинаковой толщины отражает варьирование густоты стояния деревьев, связанное с их неравномерным размещением по площади. Такое же положение наблюдается в совокупностях древостоев одинакового возраста, произрастающих в однородных лесорастительных условиях.

В таблице приведены данные высот и распределения количества деревьев по ступеням толщины в древостоях сосняка ягодникового 45-летнего возраста различной густоты.

Высоты и количество деревьев по ступеням диаметра в 45-летних древостоях разной густоты

\begin{tabular}{|c|c|c|c|c|c|c|c|c|c|}
\hline \multirow{2}{*}{$\begin{array}{c}\text { Ступени } \\
\text { толщины, } \\
\text { см }\end{array}$} & \multicolumn{2}{|c|}{ Густота 4172 шт/га } & \multicolumn{3}{|c|}{ Густота 3112 шт/га } & \multicolumn{3}{|c|}{ Густота 2748 шт/га } \\
\hline & $\begin{array}{c}\text { число ство- } \\
\text { лот/га }\end{array}$ & $\begin{array}{c}\text { ранг, } \\
\%\end{array}$ & $\begin{array}{c}\text { высо- } \\
\text { та, }\end{array}$ & $\begin{array}{c}\text { число ство- } \\
\text { лов, шт/га }\end{array}$ & $\begin{array}{c}\text { ранг, } \\
\%\end{array}$ & $\begin{array}{c}\text { высо- } \\
\text { та, м }\end{array}$ & $\begin{array}{c}\text { число ство- } \\
\text { лов, шт/га }\end{array}$ & $\begin{array}{c}\text { ранг, } \\
\%\end{array}$ & $\begin{array}{c}\text { высо- } \\
\text { та, м }\end{array}$ \\
\hline 4 & 500 & 12,0 & 10,3 & 392 & 12,6 & 9,0 & 337 & 12,2 & 8,1 \\
\hline 6 & 929 & 34,2 & 11,5 & 636 & 33,0 & 10,4 & 531 & 31,5 & 9,5 \\
\hline 8 & 886 & 55,4 & 12,5 & 582 & 51,2 & 11,5 & 431 & 47,2 & 10,8 \\
\hline 10 & 800 & 74,6 & 13,3 & 454 & 66,3 & 12,5 & 337 & 59,5 & 11,9 \\
\hline 12 & 557 & 88,0 & 13,9 & 368 & 78,1 & 13,4 & 325 & 71,3 & 12,8 \\
\hline 14 & 286 & 94,9 & 14,5 & 292 & 87,5 & 14,2 & 269 & 81,1 & 13,8 \\
\hline 16 & 157 & 98,7 & 15,0 & 204 & 94,1 & 14,8 & 243 & 89,9 & 14,5 \\
\hline 18 & 29 & 99,4 & 15,4 & 98 & 97,2 & 15,2 & 169 & 96,1 & 15,2 \\
\hline 20 & 28 & 100,0 & 15,8 & 64 & 99,3 & 15,8 & 38 & 97,5 & 15,7 \\
\hline 22 & - & - & - & 22 & 100,0 & 16,3 & 31 & 98,5 & 16,1 \\
\hline 24 & - & - & - & & & & 25 & 99,5 & 16,4 \\
\hline 26 & - & - & - & & & & 12 & 100,0 & 16,7 \\
\hline
\end{tabular}


Анализируя табличные данные, можно констатировать, что густота древостоев является существенным фактором, влияющим на их таксационную структуру. В частности, она заметно снижает интенсивность прироста деревьев по толщине. По материалам, приведенным в таблице, доминирующие деревья в загущенном древостое (с количеством деревьев 4172 шт/га) представлены ступенью толщины 20 см, в древостое со средней густотой (3112 шт/га) - ступенью 22 см, а в редком (2748 шт/га) - ступенью 26 см. При сравнении средних высот деревьев одних и тех же ступеней толщины обнаруживается, что они закономерно повышаются от редкого древостоя к густому. В этом же направлении (от редкого древостоя к густому) повышается ранг деревьев (их положение в ряду процентного распределения количества стволов) одинаковой толщины. Наиболее четко это проявляется в средних ступенях диаметра. Результаты исследований свидетельствуют, что отмеченные выше закономерности проявляются в насаждениях всех типов леса и классов бонитета. Это дает основание утверждать о наличии общей (природной) закономерности в динамике рангов деревьев одинакового диаметра, обусловленной плотностью их стояния в древостое, то есть о густотном изменении (сдвиге) рангов.

Как правило, деревья с более высоким рангом в насаждениях характеризуются меньшей угнетенностью. Однако в случае с густотным сдвигом рангов более высокий ранг не является показателем доминирования деревьев по развитию крон. В густых и перегущенных древостоях конкурентные взаимоотношения между деревьями за ресурсы местообитания выражены в значительно большей степени, чем в менее густых. При густом стоянии деревья подвержены большему угнетению со стороны «соседей» и поэтому характеризуются меньшими размерами крон. Подтверждение этому, в частности, можно получить из материалов анализируемой таблицы. В специальной литературе отмечается, что положение дерева в древостое, его угнетённость достаточно надежно характеризуются относительным диаметром [6, 7]. Наименьшие значения этого показателя присущи угнетенным, отмирающим деревьям. По данным таблицы относительный диаметр (отношение D:H) у деревьев одного и того же диаметра закономерно уменьшается с увеличением густоты древостоев. Так, этот показатель у деревьев диаметром 10 см в редком древостое составляет 0,84 см/м, в древостое со средней густотой $-0,80 \mathrm{~cm} / \mathrm{M}$, а в густом $-0,75 \mathrm{~cm} / \mathrm{M}$.

При различной степени загущенности деревья одного и того возраста могут иметь одинаковую толщину. Однако в густом стоянии по сравнению с редким, эти деревья будут отличаться или лучшими наследственными свойствами, или более качественными условиями микросреды. Можно предположить, что в обоих случаях они будут характеризоваться более высокими значениями высоты, чем деревья менее стесненных условий. Такое положение связано с разной степенью влияния густоты на прирост диаметра и высоты деревьев. Известно, что при густом стоянии рост деревьев по диаметру замедляется в большей степени, чем по высоте. Следовательно, в одновозрастных древостоях деревья одного и того же диаметра, отличающиеся более низкими высотами, находятся в менее стеснённом состоянии и, как следствие, характеризуются большими размерами крон.

Таким образом, дифференциация фитомассы крон, связанная с наследственными особенностями, ресурсами микросреды и плотностью стояния деревьев в древостоях одного возраста и класса бонитета может быть корректно опосредована соотношением диаметра и высоты стволов.

Известно, что объем ствола определяется тремя таксационными показателями: диаметром, высотой и формой. Многими исследованиями доказано, что коэффициенты формы древесных стволов обладают небольшой изменчивостью [1]. Поэтому независимо от лесорастительных условий, возраста и полноты древостоев диаметр и высота стволов практически полностью объясняют варьирование их объемов, а следовательно, и фитомассы. В то же время c общебиологических позиций степень дифференциации и изменчивости размеров крон деревьев в больших совокупностях насаждений, не однородных по возрасту и условиям местопроизрастания, не может быть связана только линейными показателями (высотой и диаметров) стволов. Это объясняется тем, что диаметр и высота стволов в совокупностях насаждений разного возраста и различных классов бонитета не могут однозначно характеризовать ранг деревьев. В частности, это подтверждается данными нижеприведённого рисунка, на котором в сосняках ягодникового и брусничникового типов леса разного возраста, показано изменение рангов деревьев по диаметру. 


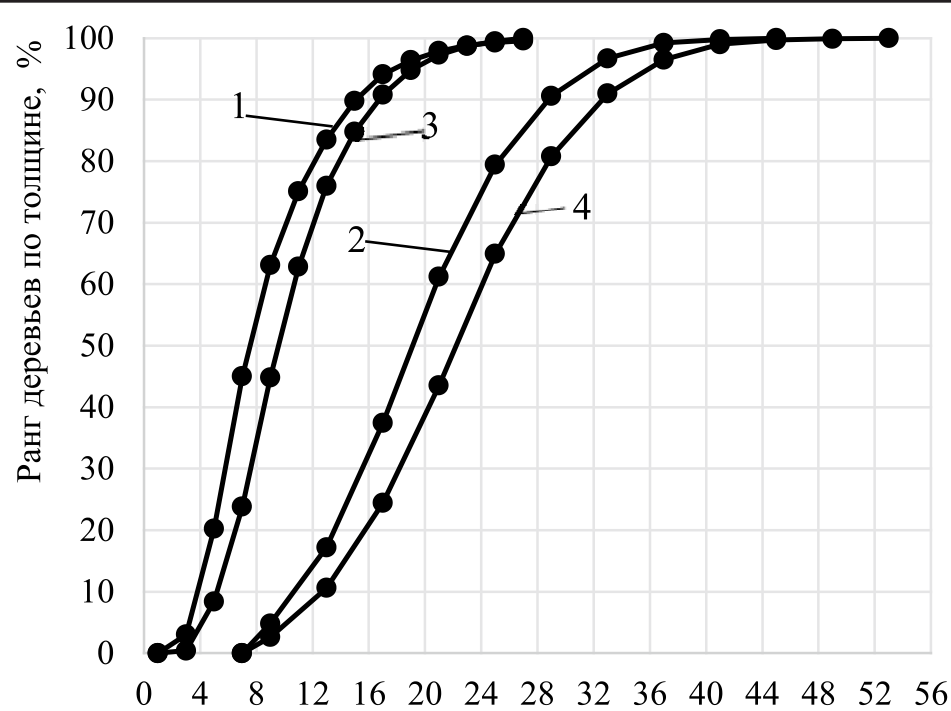

Диаметр деревьев, см

\begin{abstract}
Изменение рангов деревьев по диаметру в исследуемых сосняках: 1 - сосняк брусничниковый, возраст 40 лет; 2 - сосняк брусничниковый, возраст 100 лет; 3 - сосняк ягодниковый, возраст 40 лет; 4 - сосняк ягодниковый, возраст 100 лет
\end{abstract}

При построении линий, показывающих динамику рангов, использованы ранее опубликованные нами материалы, содержащие ряды процентного распределения количества деревьев по ступеням диаметра [3]. Как видно из данных рисунка, в древостоях конкретного типа леса ранги деревьев, характеризующихся одинаковой толщиной, заметно снижаются по мере увеличения их возраста. Например, деревья диаметром 16 см в древостоях сосняка брусничникового в 40-летнем возрасте имеют ранг 93\%, а 100-летнем только $34 \%$. Они в 40-летних древостоях занимают господствующее положение и отличаются крупными, хорошо развитыми кронами. В 100-летних древостоях такие деревья относятся к категории угнетенных и характеризуются малыми размерами крон.

На основе специальных расчетов установлено, что ранги деревьев одинакового диаметра на каждые 10 лет увеличения возраста древостоев в различных типах леса уменьшаются на 10-15\%. Это свидетельствует о том, что в онтогенезе древостоев наблюдается возрастное изменение (возрастной сдвиг) рангов деревьев одинаковой толщины. Данное обстоятельство отмечается также другими исследователями, но без указания каких-либо количественных показателей [8].

Из данных рисунка видно, что деревья одинаковой толщины в разных типах леса характеризуются различным ранговым по- ложением. Равновеликие по диаметру деревья, при прочих равных условиях, в лучших условиях местопроизрастания имеют меньший ранг, чем в более худших. Например, деревья диаметром 12 см в 40-летних древостоях сосняка ягодникового имеют ранг $68 \%$, такие же деревья в брусничниковом типе леса $-78 \%$. Эти различия сглаживаются в крупномерных и маломерных ступенях диаметра. Выявляется, что при прочих равных условиях деревья, диаметр которых в определенных лесорастительных условиях соответствует 50-му рангу, с повышением бонитета на один класс характеризуется рангом на 10-12\%. Приведенные материалы свидетельствуют, что с изменением качества лесорастительных условий (классов бонитета) также наблюдается сдвиг ранга равновеликих по диаметру деревьев. Таким образом, можно констатировать об экологическом сдвиге рангов деревьев одинакового диаметра.

\section{Заключение}

По результатам настоящих исследований можно сделать следующие обобщения. Дифференциация размеров стволов и крон, связанная с наследственными особенностями, ресурсами микросреды и плотностью стояния деревьев в древостоях одного возраста и класса бонитета, может быть корректно опосредована соотношением диаметра и высоты стволов. 
Ранг деревьев одинаковой толщины и их положение в пологе изменяются в зависимости от условий местопроизрастания (типов леса), возраста и густоты древостоев. В онтогенезе древостоев наблюдаются экологический, возрастной и густотный сдвиги рангов деревьев одинакового диаметра.

Изменчивость массы крон, а следовательно, их структурных частей (ветвей, хвои и генеративных органов) корректно связывать с высотой и диаметром деревьев, только в древостоях одного типа леса при незначительной возрастной гетерогенности деревьев. Оценка изменчивости и особенностей накопления фитомассы крон в рамках естественных возрастных рядов роста и развития древостоев (в древостоях одного возраста, произрастающих в однородных лесорастительных условиях), корректно проводить с учетом возраста, диаметра и высоты деревьев. В подобных исследованиях, охватывающих множество естественных рядов развития, возникает необходимость в использовании дополнительного показателя, характеризующего качество условий местопроизрастания - класса бонитета насаждений.

Таким образом, при оценке надземной фитомассы деревьев по фракциям на основе уравнений множественной регрессии в качестве определяющих факторов (независимых переменных) необходимо использовать диаметр, высоту и возраст деревьев, а также показатель, характеризующий лесорастительные условия.

\section{Список литературы}

1. Кузьмичёв В.В. Закономерности динамики древостоев: принципы и модели. Новосибирск: Наука, 2013. 208 с.

Kuzmichev V.V. Regularities of a tree stands' dynamics: principles and models. Novosibirsk: Nauka, 2013. 207 p. (in Russian).

2. Усольцев В.А., Гаврилин Д.С., Субботин К.С. Фитомасса деревьев лиственницы на северном и южном пределах и составление справочно-нормативных таблиц // Эко-потенциал. 2015. № 2 (10). С. 7-16.

Usoltsev V.A., Gavrilin D.S., Subbotin K.S. Larch tree biomass on the northern and southern limits and designing of standard and reference tables // Eko-potentsial. 2015. № 2 (10). P. 7-16 (in Russian).

3. Нагимов 3.Я. Закономерности роста и формирования надземной фитомассы сосновых древостоев: дис. ... докт. сельхоз. наук. Екатеринбург, 2000. 409 с.

Nagimov Z.Ya. Regularities of growth and formation of aboveground phytomass of pine stands: dis. ... dokt s.-kh. nauk. Yekaterinburg, 2000. 409 p. (in Russian).

4. Нагимов 3.Я., Артемьева И.Н., Нагимов В.З. Структура и динамика надземной фитомассы сосновых древостоев лишайникового типа леса // Известия высших учебных заведений. Лесной журнал. 2012. № 5 (329). С. 60-66.

Nagimov Z.Ya., Artemeva I.N., Nagimov V.Z. Structure and dynamics of top phytomass of pine stands in lichen forests // Izvestiya vysshikh uchebnykh zavedeniy. Lesnoy zhurnal. 2012. № 5 (329). P. 60-66 (in Russian).

5. Стоноженко Л.В., Югов А.Н., Карминов В.Н., Иванов Н.Г. Применение MS Excel и Statistica for Windows для лесотаксационных вычислений и обработки экспериментальных данных методами математической статистики. М.: МГТУ им. Н.Э. Баумана, 2012. 88 с.

Stonozhenko L.V., Yugov A.N., Karminov V.N., Ivanov N.G. Application of MS Excel and Statistica for Windows for forest-taxational calculations and processing of experimental data by methods of mathematical statistics. M.: MGTU im. N.E. Baumana, 2012. 88 p. (in Russian).

6. Вайс A.А. Научные основы оценки горизонтальной структуры древостоев для повышения их устойчивости и продуктивности: на примере насаждений Западной и Восточной Сибири: дис. ... докт. сельхоз. наук. Красноярск, 2014. $418 \mathrm{c}$

Weiss A.A. Scientific bases for assessing the horizontal structure of stands for increasing their stability and productivity: on the example of plantings in Western and Eastern Siberia: dis. ... dokt. selkhoz. nauk. Krasnoyarsk, 2014. 418 p. (in Russian).

7. Нуриев Д.Н. Строение, рост и состояние озеленительных посадок березы повислой (Betula pendula Roth) в условиях г. Екатеринбурга: дис. ... канд. сельхоз. наук. Екатеринбург, 2019. $171 \mathrm{c.}$

Nuriev D.N. Structure, growth and condition of landscaping plantings of the hanging birch (Betula pendula Roth) in the conditions of Yekaterinburg: dis. ... kand. selkhoz. nauk. Yekaterinburg, 2019. 171 p. (in Russian).

8. Семечкина М.Г. Структура фитомассы сосняков. Новосибирск: Наука, 1978. 165 с.

Semechkina M.G. The structure of the phytomass of pine forests. Novosibirsk: Nauka, 1978. 165 p. (in Russian). 